University of San Diego

Digital USD

Spring 5-26-2018

\title{
Management of Chronic Low Back Pain with a Nonpharmacological Pain Management Kit Among Military Personnel
}

\author{
Heidi M. Sterling BSN, RN, DNP Student \\ University of San Diego, Hahn School of Nursing and Health Science, hsterling@sandiego.edu \\ Karen A. Macauley PhD, DNP, FNP-BC, GNP-BC \\ University of San Diego, Hahn School of Nursing and Health Science, kmacauley@sandiego.edu \\ Robert Topp PhD, RN \\ University of San Diego, Hahn School of Nursing and Health Science, rtopp@sandiego.edu
}

Follow this and additional works at: https://digital.sandiego.edu/dnp

Part of the Nursing Commons, and the Rehabilitation and Therapy Commons

\section{Digital USD Citation}

Sterling, Heidi M. BSN, RN, DNP Student; Macauley, Karen A. PhD, DNP, FNP-BC, GNP-BC; and Topp, Robert $\mathrm{PhD}, \mathrm{RN}$, "Management of Chronic Low Back Pain with a Nonpharmacological Pain Management Kit Among Military Personnel" (2018). Doctor of Nursing Practice Final Manuscripts. 63.

https://digital.sandiego.edu/dnp/63

This Doctor of Nursing Practice Final Manuscript is brought to you for free and open access by the Theses and Dissertations at Digital USD. It has been accepted for inclusion in Doctor of Nursing Practice Final Manuscripts by an authorized administrator of Digital USD. For more information, please contact digital@sandiego.edu. 
Running head: MANAGEMENT OF CHRONIC LOW BACK PAIN

Management of Chronic Low Back Pain with a Nonpharmacological

Pain Management Kit Among Military Personnel

Heidi M. Sterling BSN, RN, DNP Student, Robert Topp, PhD, RN, Karen A. Macauley, PhD, DNP, FNP-BC, GNP-BC 
Management of Chronic Low Back Pain with a Nonpharmacological Pain Management Kit

\section{Among Military Personnel}

\section{Introduction}

Chronic musculoskeletal pain is a persistent, debilitating condition that influences an individual's ability to carry out the necessary and desired activities of daily living. Back pain is the second leading cause of disability in the United States, affecting 17 percent of Americans (Brault, 2009). Low back pain (LBP) specifically, is the fifth most frequent reason for medicaloffice visits, being one of the most common and expensive causes of work-related disability (Deyo, Mirza, \& Martin, 2006). Low back pain is defined as pain, muscle tension, or stiffness localized below the costal margin and above the inferior gluteal folds, with or without sciatica. It commonly has no identifiable pathology (e.g., infection, tumor, osteoporosis, rheumatoid arthritis, fracture, inflammation) (Chou, 2011). Low back pain is defined as chronic when it persists for 12 weeks or more (Chou, 2011).

Opioid medications are commonly prescribed to treat chronic low back pain (CLBP) and can be a dangerous and addictive remedy if not appropriately consumed (Centers for Disease Control and Prevention, 2016a). According to the CDC, the United States is currently undergoing an "opioid epidemic." Since 1999 opioid overdose deaths have quadrupled, with 91 Americans dying per day from opioids, including prescription opioids (Center for Disease Control and Prevention, 2016). Furthermore, the side effects associated with opioid use are not limited to addiction and overdose, but can also include; depression, tolerance, increased sensitivity to pain, physical dependence, drowsiness, and confusion (Centers for Disease Control and Prevention, 2016b). In a recent publication on treatment guidelines for CLBP by the American College of Physicians (Qaseem, Wilt, McLean, Forciea, \& Clinical Guidelines 
Committee of the American College of, 2017), non-pharmacological interventions were recommended as first line treatment for CLBP. The guidelines also state that opioids should only be used as a last resort and only if the benefits of use outweigh their risks.

Chronic low back pain impacts a variety of individuals. Similar to that of the civilian world, CLBP also greatly impacts unique populations such as United States Active Duty Military Personnel (ADMP) (Knox et al., 2011). Injuries to the low back among this group of individuals can be devastating. Soldiers who sustain a low back injury have been shown to have an 85 percent chance of not returning to their combat area after sustaining the injury (Cohen et al., 2009).

Furthermore, an internal Army investigation report found that up to 35 percent of wounded, hospitalized soldiers are addicted to narcotics due to sustained injuries (Zoroya, 2011). In addition, those who remain active duty opioid use is not typically a viable option for treatment. The physical demands placed upon ADMP requires them to avoid opioid use to maintain combat readiness. Thus, alternative treatment modalities for these individuals are essential to maintain a high level of physical functioning while enduring untreated chronic pain or resign from their participation in their military unit (Office of the Army Surgeon General, 2010).

\section{Description of the project}

In order to maintain the required high level of physical functioning and rank of ADMP, effective non-narcotic interventions to managing CLBP need to be utilized. The NonPharmacological Pain Management Kit (NPMK) is a kit composed of five non-pharmacological interventions that have individually shown to reduce chronic pain. The kit consists of a topical analgesic (BioFreeze), kinesiology tape, thermotherapy (hot and cold), and specific low back 
therapeutic exercises. The kit also contains behavioral components such as directions for obtaining a program buddy, setting goals, and utilizing a daily diary. These components will assist in compliance and commitment to achieve an individual-defined manageable pain level. Finally, an instruction booklet (Appendix B) will be included that will provide educational materials regarding all components. The NPMK is an individualized approach that is intended to compliment one's current treatment routine. Several different populations experiencing CLBP, including ADMP, can utilize the NPMK independently.

\section{Proposed Evidence-based Solution}

Several search engines have been utilized to obtain the literature regarding each of the five non-pharmacological interventions located in the NPMK. PubMed, CINHAL Plus, Cochrane Central Register of Controlled Trials, Cochrane Database of Systematic Reviews, and Google Scholar were all key databases that were used. Common search terms utilized within these databases were; topical analgesic, BioFreeze, kinesiology tape, thermotherapy, heat therapy, cold therapy, low back exercise, TheraBand, reduction of chronic low back pain, and chronic pain. Due to multiple interventions being used in the proposed project, several articles were reviewed and 35 were eventually utilized for the project and supporting evidence.

\section{Topical Analgesic}

Menthol is an ingredient that is commonly used in topical analgesics such as BioFreeze. The application of menthol is a form of cryotherapy, which decreases arterial blood flow to an affected site limiting inflammation (Thorlacius, Vollmar, Westermann, Torkvist, \& Menger, 1998). Menthol, applied topically to the skin has been shown to stimulate thermoreceptors in the skin, similar to the effect of topical ice, leading to vasoconstriction and decrease in blood flow (Olive, Hollis, Mattson, \& Topp, 2010). 
In a randomized control trial (RCT) by Topp, Ledford, and Jacks (2013) there was a reduction in radial artery blood flow and patient discomfort with Menthol application. Another RCT by Zhang, Enix, Snyder, Giggey, \& Tepe (2008) compared a group of individuals with low back pain who received chiropractic therapy two times a week with those who received chiropractic therapy two times a week and applied menthol ointment three times per day. The experimental group that utilized the menthol gel reported a significant pain reduction compared to those who only received chiropractic adjustments. Finally, a third article and triple blind RCT, tested a topical menthol product on workers with chronic and neuropathic pain of the arm and hand (carpel tunnel syndrome). The experimental group received the menthol treatment during their workday, while the control group received a placebo at the same time. The outcome showed a greater reduction in pain within the experimental group, proving that the non-pharmacological menthol product was effective in managing the subject's pain (Sundstrup et al., 2014).

\section{Kinesiology Tape}

Various applications of tape have been used to provide stability and support to injured areas of the body. Therapeutic taping with kinesiology tape involves a thinner, more elastic tape than conventional tape, which can be stretched $120 \%$ to $140 \%$ of its original length. The tape is attached to the skin, and allows for less mechanical restraint and restriction of mobility than conventional tape (Castro-Sánchez et al., 2012; Kase, 2003). The application of kinesiology tape is described to promote normalization of muscular function, increase lymphatic and vascular flow, reduce pain, and help correct possible joint misalignments (Kase, 2003).

Lim and Tay (2015) conducted a systematic review and meta-analysis that analyzed 17 RCT's focusing on chronic pain and disability greater than four weeks. Through their analysis they found that the use of kinesiology tape to be beneficial compared to other minimal 
interventions such as no taping or sham taping applications. They also found that kinesiology taping in conjunction with other therapies such as exercise has assisted with a reduction in musculoskeletal pain, rather than exercise alone. Bae, Lee, Oh, and Kim (2013) conducted a RCT that compared CLBP patients who received the application of kinesiology tape and physical therapy to CLBP who received only physical therapy. These researchers recognized that individuals with CLBP have poor control of postural muscles due to changes in muscle coordination and neural transmission due to pain. The results of this study indicated that subjects who received kinesiology tape and physical therapy reported reduced pain, better postural control, and better movement. In a similar study, other investigators (Castro-Sánchez et al., 2012) reported that CLBP patients who received the kinesiology tape application decreased their disability and pain, and reported greater muscle endurance than the control group who received a sham tape condition. Finally, consistent with the previous findings, Homayouni et al. (2016) applied kinesiology tape to subjects suffering with pes anserinus tendino-bursitis and compared it to a control group who received non-steroidal anti-inflammatory medication and physical therapy. Both groups reported reductions of pain and swelling. The experimental group with kinesiology tape however, had significantly more success showing the greatest reduction in pain and swelling following treatment.

\section{Thermotherapy}

Thermotherapy is the application of either heat or cold to the skin and has been a longstanding treatment modality for a number of physical ailments (Malanga, Yan, \& Stark; Petrofsky, Laymon, Alshammari, \& Lee, 2016). Heat has been shown to increase healing by promoting blood flow to the applied area, as well as reducing pain (Malanga et al., 2015). In a randomized double-blinded control trial by Petrofsky, Laymon, Alshammari, and Lee (2016) 
low-level continuous heat was utilized in conjunction with home exercise and physical therapy on the knees. This intervention resulted in better pain control, a significant increase in active range of motion (AROM) and strength, and greater home exercise compliance. In a RCT by Dehghan and Farahbod (2014), heat and cold therapy with the addition of naproxen were tested on two separate groups who experienced low back pain within four weeks. A third group was tested only taking naproxen. The study concluded that the application of thermotherapy and pharmacologic treatment (naproxen) could relieve pain in patients with low back pain more than naproxen alone. Furthermore, it determined that heat relieved pain even more so than the cold therapy group.

Thermotherapy also includes cryotherapy or cold therapy, this involves the application of ice or another low-temperature substance to the skin. Cold therapy works by removing heat from the body causing a decrease in tissue temperature and blood flow as a result of vasoconstriction (Petrofsky et al., 2016). This process, reduced tissue metabolism, inflammation, oxygen utilization, and muscle spasm (Nadler, Weingand, \& Kruse, 2004). One RCT interprets the use of cryotherapy as not only being for acute pain control, but also to facilitate exercise during the rehabilitation process (Myrer, Measom, \& Fellingham, 1998). Another, RCT evaluated subjects who had experienced either back or neck strains. In this study all subjects received a dose of ibuprofen, but were also separated into two groups, one that received a 30-minute application of heat and one that received a 30-minute cold pack application applied to the strained area. The study describes a noticeable improvement in pain, however the improvement is seen among both heat and cold application groups. The study also mentions that the majority of participants were satisfied with their pain reduction to a point where they would use the same therapy if injured again (Garra et al., 2010). 


\section{Exercise}

Various forms of exercise have been utilized to manage CLBP including aerobic exercise, muscle strengthening, and stretching and flexibility exercises (Hayden, van Tulder, Malmivaara, \& Koes, 2005). Aerobic exercise increases blood flow to the low back improving the healing process and reducing the stiffness that contributes to CLBP (Hayden et al.). It also has been shown to increase the body's natural production of endorphins, causing a similar chemical reaction that is elicited when taking actual pain medication (Ullrich, 2009). Furthermore, CLBP patients tend to restrict their trunk movement to reduce their pain in the lumbar-sacral area, this reduces core strength and increases lumbar instability resulting in low back pain (Danneels, Vanderstraeten, Cambier, Witvrouw, \& De Cuyper, 2000).

Considering these concepts, exercise to activate and strengthen the abdominal muscles is crucial for supporting the lumbar spine to reduce pain (Amit, 2013). In addition, stretching the soft tissues in the back, legs, and buttock can help to mobilize the spine, resulting in an increase in range of motion and also assisting in reducing back pain (Ullrich, 2014). Increased range of motion assists with patient's movement and activities of daily living, as these everyday activities require complex movements of these areas (Li, McClure, \& Pratt, 1996). Hayden, Van Tulder, Mamivaara, and Koes (2005) analyzed 43 trials including RCT's and determined that exercise therapy reduced pain and functional limitations in those with CLBP. In another systematic review assessing the effects of exercise by Gordon and Bloxham (2016), muscular strength programs, flexibility, and aerobic exercise were found to be individually beneficial for nonspecific CLBP. While the review determined each intervention successful, it also noted that future study should be aimed at combining the three elements of muscular strength, flexibility, and aerobic exercise into one program, a current limitation. 


\section{Behavioral}

A number of factors have been found to affect an individual's decision to engage in recommended health behaviors including treatments for CLBP. Self-efficacy, conceptualized by Bandura (2012) is the confidence that one has to successfully engage in behaviors that lead to desired outcomes and is an important predictor of health-related behaviors. Self-efficacy to manage pain has been demonstrated to be an important predictor of an individual adopting behaviors that reduce their chronic pain (Wright \& Schutte, 2014). Other investigators have found that a patient's self-efficacy to manage their pain predicts future functional ability (Craig et al., 2013; Gard \& Larsson, 2003; Sullivan, Feuerstein, Gatchel, Linton, \& Pransky, 2005). Furthermore, an individual's beliefs and attitudes also contribute to their decision to change their behavior in order to manage their pain, including anticipated benefits of and barriers to performing the behavior change (Mannion, Wieser, \& Elfering, 2013).

In a systematic review by Jordan, Holden, Mason, \& Foster (2010) the fore mentioned behavioral components are recognized to impact compliance and the success of the individual. Another RCT by Friedrich et al. (1998), an exercise program combined with a motivational program was compared to only an exercise program among those who suffer from CLBP. The study resulted in greater adherence to the exercise program and more frequent exercise among the study group that received the motivational program. Finally, in a RCT, an adherence-focused exercise program with an exercise instruction booklet also proved to demonstrate greater adherence and more minutes exercised than the non-adherence focused exercise group (Hughes et al., 2004). This study specifically notes the relation of adherence to Bandura's concept of selfefficacy (2012). The authors targeted subject's confidence in the intervention as well as the ability to maintain the exercise even in the presence of barriers. The success of the intervention 
group highlights the importance of addressing health-related behaviors (Bandura, 2012; Hughes et al., 2006).

\section{Aims/Anticipated Project Outcomes}

This non-pharmacological pain management project was anticipated to have several short-term and long-term outcomes. Due to the direct and immediate application of the interventions, the short-term outcomes had the potential to occur as early as the subject started utilizing the interventions. These desired outcomes consist of a decrease in pain level and an increase in functional ability with the utilization of the subjects chosen format of interventions. It also includes patient compliance with their format of intervention utilization as documented on their daily diary entry.

There are three long-term outcomes regarding this project that were attainable starting at four weeks. The first outcome was that pain level will be better than the patient's original pain level as determined by the Numeric Pain Rating Scale (NPRS). The second, functional ability \& ability to perform duties will be improved as determined by the Patient Specific Functional Scale (PSFS). Lastly, the patient will utilize a minimum of two of the five non-pharmacological interventions daily as documented on their daily diary entry.

\section{Anticipated Project Impact}

Considering the significance of CLBP within the military and the impact that the condition has on military personnel, it was possible that the NPMK would have a significant overall impact. As previously mentioned patients were anticipated to describe a decrease in pain and an increase in functional ability. These results could therefore have even further implications, including the ability for military personnel to function to the best of their ability, continue in their current units, and overall retention in the military. 


\section{Methods}

\section{Evidence Based Project Model}

The Iowa Model of Evidence-Based Practice to Promote Quality Care (Titler et al., 2001) is a model that guides the evidence-based practice (EBP) change process. The goal of the model is to attain beneficial patient outcomes utilizing EBP. The model has been used successfully to guide a multitude of practice changes in various multidisciplinary studies. The model begins by asking for the identification of a problem or knowledge focused trigger. It then continues through a series of steps or "feedback loops" that identify whether or not the problem is a priority to the organization, if sufficient evidence is available, determines if a change is appropriate to adopt through pilot study, institutes the final change, and then disseminates the results from the change (Melnyk, 2015).

The Iowa Model of Evidence-Based Practice to Promote Quality Care provided direction and guidance for this CLBP management project. The model incorporates "feedback loops" which helped identify the importance of addressing CLBP and acceptable treatment options within this military setting.

\section{Project Approval}

This EBP project was implemented within an active military unit and diverse population of military personnel located in the Southwest United States. Approval was granted from the unit's senior officer as well as the Navy Medical Center. IRB approval was acquired through the study University.

\section{Program Development and Implementation Timeline}

The implementation of the NPMK was conducted in a sequence of steps and activities. A flier (Appendix A) was posted at the medical unit and sent through email to the unit's medical 
staff. This flier sought individuals who were experiencing chronic musculoskeletal pain of the low back. The flyer also outlined the purpose of the project and participant involvement. Interested individuals were instructed to contact the project coordinator to discuss inclusion and exclusion criteria and to set up an initial meeting if eligible. Inclusion criteria included active duty military or retired military working on base as a civilian employee, being over the age of 18, reporting chronic musculoskeletal pain of the low back occurring longer than 12 weeks. Individuals were excluded from the project if they reported any contraindications in engaging in moderate exercise or allergies to menthol or elastic tape. At the initial meeting, baseline data were collected (demographic questionnaire, functional testing, and PSFS) and the nonpharmacological kit was provided for the patient. The patient was then educated on how to use the kit and complete the diary for the following four weeks. Data were collected for all participants enrolled in the project at three time intervals including at the initial meeting, at one week, and four weeks after the initial meeting.

\section{Intervention}

The contents of the kit included four modes of non-pharmacological interventions including; Biofreeze, Kinesiology Tape, TheraPearl (hot and cold thermal therapy), and Therabands for exercise and stretching. The project coordinator reviewed the contents of the kit and how to use each of the four interventions with each patient at the initial meeting (Appendix B). An instruction booklet outlining all instructions was also provided in written form (Appendix B). Patients were instructed to continue to follow their current management of pain along with the use of the kit. Furthermore, they were asked to attempt at use of all interventions daily and to evaluate which component worked best for their pain and lifestyle along with their existing routine. The final component of the NPMK included materials for behavioral techniques 
directed at maintaining compliance with the interventions and the patient's routine (Appendix B). During the initial meeting, patients were informed about the recommended use of the behavioral techniques including setting goals, working with a buddy, and maintaining a graph of their progress. To foster these techniques and monitor progress, patients were instructed to complete a simple daily diary for the four weeks recording average daily pain, interventions used, and pain medications taken (Appendix F).

\section{Data Collection}

Demographic information (age, gender, position, years served, duration of back pain, and acceptable pain level) was collected from all patients at baseline (Appendix C). At baseline, week one, and week four all participants completed the same data collection sequence conducted by the DNP student to evaluate the patients pain and physical functioning (Appendix E). This sequence consisted of three functional tasks included a sit and reach test, timed plank, and deadlift. The collection sequence also included a fourth tool, the PSFS to measure change in functional ability over the duration of the four weeks (Appendix D). During the duration of the four weeks data were also collected in the instructed daily diary as previously mentioned. The diary documented their average daily pain rating, interventions used, and pain medication consumed by the patient (Appendix F). Finally, an exit interview reporting the benefits and limitations of the NPMK was also completed at week four (Appendix G).

The first test of the data collection sequence, the sit and reach test, is a common test that is used to measure flexibility of the low back and hamstring muscles (Cuberek, 2013; Wood, 2008). This test was performed uniformly for all patients. In a seated position with legs extended, the patients heels were placed at the 15-inch mark of a measuring tape that was running parallel between both legs. They were then asked to place one hand over the other and 
bend forward reaching down the measuring tape as far as possible while keeping their legs straight. This therefore elicited a stretch of both the low back and hamstrings. The furthest measurement reached out of three attempts was then recorded (Cuberek, 2013; Makeoverfitness, (n.d)). Finally, the patient was then asked their level of pain while performing the movement using the standard NPRS. This scale measures pain on a numbered scale from zero to ten. Zero refers to no sensation of pain and ascends to ten being the worst possible imaginable pain (Williamson \& Hoggart, 2005).

The second test in the sequence that was utilized to determine the benefit of the NPMK is a deadlift. A deadlift evaluates strength of the core, gluteus, and low back muscles (Graham, 2000). This exercise is done in one repetition and weight is determined using the Deadlift Strength Standards chart at the Novice level in accordance to weight, age, and gender (Appendix E) (Rippetoe, 2006) (killustrated.com, (n.d.)). Prior to the assessment an instruction and demonstration of proper deadlift technique was reviewed (Graham, 2000). After the exercise was performed the patient was then asked to report their level of pain using the standard NPRS (Williamson \& Hoggart, 2005).

A timed plank was the third functional test that was evaluated at the three data points. A plank tests the strength of the core and back muscles. This was performed by holding oneself in push-up position with arms bent at 90 degrees, resting on their elbows holding the body in a straight line (Strand, Hjelm, Shoepe, \& Fajardo, 2014). The patient was instructed to hold the plank as long as possible. Two data points therefore came from this assessment, including time that the plank was held and again pain level in accordance to the NPRS (Williamson \& Hoggart, 2005). 
The final assessment tool that was used was the PSFS (Appendix B). This tool assesses activity limitations in relation to the patients CLBP. The PSFS has been used in several other projects and studies to evaluate individualized functional tasks in relation to their impairment (Horn et al., 2012; Stratford, Gill, Westaway, \& Binkley, 1995). The patient was asked to describe specific activities in their daily life that are impacted by their condition, they were then asked to rate this impairment on a scale of zero to ten, with zero being that they are unable to perform the activity ascending to ten, in which they are able to perform the activity with no difficulty as they were prior to their injury (Stratford et al., 1995).

\section{Data Analysis}

Data analysis to address the purpose of the project occurred in two steps. During the first step data were transcribed from data collection sheets to an Excel spreadsheet. Data on this spread sheet were checked against the original data collection sheets for accuracy. Following verification of the data entry, descriptive statistics were performed on the demographic data in order to describe the group participating in the project and support the external validity of the project. Repeated measures ANOVA statistics were then calculated to assess change in pain and functional ability over the three data collection points. Any significant $(p<.05)$ changes in any of these outcome variables were further explored through Tukey post hoc comparisons. Descriptive statistics were then calculated on the compliance data with the components of the pain management kit to determine the degree of exposure the patients chose with the five components. Finally, qualitative data collected during the exit interview was entered into a word document for evaluation and themes in the responses were summarized.

\section{Results}


Of the originally proposed 25 participants 14 (56\%) were initially enrolled and of this number $11(79 \%)$ completed the entire four-week program. Three patients were lost to follow-up or did not complete the four-week program. Of those 11 participants who did complete the protocol all of them reported CLBP of greater than 12 weeks duration with an average duration of 37.1 months \pm 57.32 . The reported acceptable pain level among the participants was $3.82 \pm$ 2.0. A majority of the patients were male $(\mathrm{N}=9,82 \%)$ and two females $(\mathrm{N}=2,18 \%)$. The average age of the sample was $40.55 \pm 8.95$. Ten of the 11 patients were current active duty in the military and one was retired and now a civilian employee. The average years served active duty was $19.59 \pm 8.18$.

Table 1 indicated the measure of pain and functional ability at the three data collection points being compared using the repeated measures ANOVA.

Table 1. Outcome Measures Over Time

\begin{tabular}{|l|l|l|l|}
\hline Outcome measure & $\begin{array}{l}\text { Baseline } \\
\text { Mean } \pm \text { SD }\end{array}$ & $\begin{array}{l}\text { 1-Week } \\
\text { Mean } \pm \text { SD }\end{array}$ & $\begin{array}{l}\text { 4-week } \\
\text { Mean } \pm \text { SD }\end{array}$ \\
\hline Sit \& Reach (cm) & $35.77 \pm 7.37$ & $39.64 \pm 7.94$ & $43.91 \pm 6.77^{*}$ \\
\hline Timed Plank (seconds) & $155.36 \pm 88.75$ & $152.64 \pm 73.68$ & $176.72 \pm 96.89$ \\
\hline PSFS & $6.09 \pm 2.1$ & $6.465 \pm 2.07$ & $7.97 \pm 1.69^{*}$ \\
\hline Pain Rating During Sit \& Reach & $3.30 \pm 1.86$ & $2.40 \pm 1.72$ & $1.65 \pm 1.94^{*}$ \\
\hline Pain Rating During Timed Plank & $3.50 \pm 2.46$ & $3.20 \pm 1.86$ & $2.95 \pm 2.01$ \\
\hline Pain Rating During Dead Lift & $3.27 \pm 2.28$ & $2.55 \pm 2.46$ & $2.27 \pm 2.80$ \\
\hline
\end{tabular}

Note; $*$ indicates a significant $(\mathrm{p}<.05)$ change from baseline measure

Average distance reached when performing the sit and reach improved from baseline $(35.77 \mathrm{~cm})$ and week one $(39.64 \mathrm{~cm})$ to week four $(43.91 \mathrm{~cm})$. As the timed plank determined no difference in time held, it did depict an upward trend from week one with an average of 152.64 
seconds held to week four with an average of 176.73 seconds held. Finally, the PSFS was measuring functional ability resulted in no change between baseline and week one, but a reported positive change by week four averaging 6.09 at baseline to 7.97 on the scale at week four.

A repeated measures ANOVA was conducted on pain during the three functional tests. The sit and reach resulted in a statistically significant change in pain from baseline averaging 3.3 and then 1.65 at week four on the NPRS. Both deadlift and timed plank trended in the downward direction over the four weeks.

Table 2 presents the compliance data with the components of the pain management kit. This table indicates that the most frequently used component of the kit was exercise.

Table 2. Average Pain Management Components Used Per Week of The Project

\begin{tabular}{|l|l|l|l|}
\hline Pain Management Kit Component & Mean \pm SD & Maximum & Minimum \\
\hline Topical Menthol & $3.13 \pm .18$ & 7.0 & 0.0 \\
\hline Kinesiology Tape & $2.68 \pm .75$ & 7.0 & 0.0 \\
\hline Thermal Therapy & $3.43 \pm .28$ & 7.0 & 0.0 \\
\hline Exercise & $5.16 \pm .41$ & 7.0 & 2.0 \\
\hline
\end{tabular}

Compliance varied weekly among the interventions. Exercise had the greatest level of compliance each week averaging 5.16 times per week. The second most commonly used intervention was thermal therapy at 3.43, followed by Biofreeze at 3.13, and finally, least used Kineseology Tape at 2.68 times per week.

Qualitative data was collected from the exit interview conducted at week four. This data was in response to patient recommended changes in the kit, what they found most valuable, and overall impression of the NPMK. Among the various responses ADMP reported that the kit was 
"versatile," "helped with general pain and recovery," and was "convenient allowing for home exercise and travel." One of the participants noted that he did not know that "exercise could benefit his back problem not inhibit it." Finally, some of the recommendations was that they "did not necessarily feel as if the Kinesiology Tape was beneficial or needed to be included," and that "a massage roller may be beneficial."

\section{Cost/Benefit Analysis}

The purpose of this project was to promote the ability for ADMP who suffer from CLBP to function to the best of their ability and at their required duty standards. This was attempted by assisting in controlling pain and increasing functional ability through the use of the NPMK. The average cost to train an active duty soldier has been determined to be $\$ 35,000$ (Thomas, 2004). For more specialized soldiers such as Navy Seals costs can go upwards to $\$ 500,000$ (Gaskell, 2009). The success of this project will promote the retention of soldiers, prevent the waste of training funds, eliminate further need for additional medical treatment, and promote the soldier's overall well-being.

For this specific EBP project and cost analysis, the cost benefit will be evaluated looking at the average cost to train a standard soldier $(\$ 35,000)$. It was estimated that the total cost of the resources and kit over the four-week project duration was $\$ 50.00$ per person. Considering this, if the utilization of the NPMK were to prevent military personnel dropout, the cost savings therefore would be astounding at $\$ 384,450.00$ (Table 3). Due to the resources being at no cost for this specific EBP project however, the potential savings would be $\$ 385,000.00$.

\section{Discussion}

The current findings of this project indicate that use of the NPMK by ADMP reduces pain and increases functional ability. A common trend between both functional tests and pain levels indicates that the intervention was most effective with commitment and compliance for 
more than one week. While immediate benefits may have been noticeable with some patients, it was the compliance with the routine that resulted in the greatest benefit. This was similar in the previously mentioned article by Jordan et al. (2010) that determined the greater the compliance, the greater the success of the patient.

Speaking with those interested in participating, patients, and medical staff, there appeared to be a misconception among the military personnel that reporting injuries would go on their medical record and could inhibit duty assignment. As this notion was inaccurate as there was no direct communication with the patient's permanent medical record, this may have impacted enrollment numbers. Furthermore, this concept may have also been directly related to the high average age and years served, as those who were more senior ranking seemed to be understanding of this and/or have less concern for possible impact on medical records as they were approaching retirement.

While the quantitative results of the project depicted positive trends in pain and functional ability, the qualitative data that was collected at the time of the exit interview was also beneficial. This data supported both the use of the interventions in the NPMK kit and the education that was provided. For example, correcting one participants perception that he should refrain from exercise due to his condition, but rather should continue some form of movement and exercise as the literature and guidelines recommend could help his CLBP (Gordon \& Bloxham, 2016; Hayden et al., 2005; Qaseem et al., 2017). The positive qualitative feedback alone, supported the implications of this project and the benefits alternative nonpharmacological pain management interventions and the proper education of their use for CLBP.

\section{Sustainability/Implications for Practice}


The positive effects of this NPMK can impact the ADMP population with CLBP. The resources within the kit are commonly found in military facilities or can easily be obtained by the individual in retail pharmacies or stores. The interventions can therefore continue to be implemented by those who are treating CLBP and used by those who are affected by CLBP in the military setting.

Finally, while the results of this EBP project can be beneficial for the military, implications may translate to the civilian population who suffer from CLBP within our country. Healthcare providers can easily recommend the interventions within the kit as a non-opioid treatment option to manage CLBP. Furthermore, the accessibility and ease of obtaining the intervention products can easily be sought out and applied by the average person.

\section{Limitations}

While several encouraging findings resulted from this EBP project, there were multiple limiting factors that could potentially affect the validity of the findings. First, the sample size was small at 11 patients. The small sample size resulted in a limited amount of data, which may have inhibited trending progressions from reaching significant effect sizes. The second potential limitation was the variable physical conditions of the patients. This may have been related to the higher average age $(40.55 \pm 8.95)$, years served $(19.59 \pm 8.18)$, and duty position of participants who presented for the project. While several of these patients were physically active with previous or current deployments and in good physical condition, several were in administration and in leadership positions which do not require peak physical conditions. Finally, during the course of the four-week intervention period, data collection was intended to be completed both at day seven (week one) and day 28 (week four), this however was not always practical due to the 
rigorous and conflicting schedules of the ADMP. This therefore could have captured data at slightly variable time points and could have impacted precise outcome.

\section{Conclusion}

CLBP is not only a significant problem among the civilian population within the United States, but is also among the ADMP. This therefore, has left a need for a resolution that can provide pain relief and enhanced functional ability to this group of individuals. The components of the NPMK; Biofreeze, Kinesiology tape, thermotherapy, exercise, and behavioral components, offer an individual the opportunity to combine non-pharmacological, efficacious components to their current treatment routine. This can provide a safe and enhanced painrelieving effect, and lead to the ultimate goal of allowing those who serve in the United States Military to function to the best of their ability. 


\section{References}

Amit, K., Manish, G., \& Taruna, K. (2013). Effect of trunk muscles stabilization exercises and general exercises on pain in recurrent non specific low back ache. International Research Journal of Medical Sciences, 1(6), 23-26.

Bae, S. H., Lee, J. H., Oh, K. A., \& Kim, K. Y. (2013). The effects of kinesio taping on potential in chronic low back pain patients anticipatory postural control and cerebral cortex. $J$ Phys Ther Sci, 25(11), 1367-1371. doi:10.1589/jpts.25.1367

Bandura, A. (2012). On the functional properties of perceived self-efficacy revisited. Journal of management, 38(1), 9-44.

Brault, M. W., Hootman, J., Helmick, C.G.,Theis, K.A., (2009). Prevalence and Most Common Causes of Disability Among Adults--United States, 2005. Morbidity and Mortality Weekly Report (CDC), 58(16), 421-426.

Castro-Sánchez, A. M., Lara-Palomo, I. C., Matarán-Peñarrocha, G. A., Fernández-Sánchez, M., Sánchez-Labraca, N., \& Arroyo-Morales, M. (2012). Kinesio Taping reduces disability and pain slightly in chronic non-specific low back pain: a randomised trial. Journal of physiotherapy, 58(2), 89-95.

Chou, R. (2011). Low Back Pain (Chronic). American Family Physician, 84(4), 437-438.

Cohen, S. P., Nguyen, C., Kapoor, S. G., Anderson-Barnes, V. C., Foster, L., Shields, C., . . . Plunkett, A. (2009). Back pain during war: an analysis of factors affecting outcome. Archives of internal medicine, 169(20), 1916-1923.

Craig, A., Tran, Y., Siddall, P., Wijesuriya, N., Lovas, J., Bartrop, R., \& Middleton, J. (2013). Developing a model of associations between chronic pain, depressive mood, chronic 
fatigue, and self-efficacy in people with spinal cord injury. The Journal of Pain, 14(9), 911-920.

Cuberek, R., Machova, I., Lipenska, M. (2013). RELIABILITY OF V SIT-AND-REACH TEST USED FOR FLEXIBILITY SELF-ASSESSMENT IN FEMALES. Acta Gymnica, 43(1).

Danneels, L. A., Vanderstraeten, G. G., Cambier, D. C., Witvrouw, E. E., \& De Cuyper, H. J. (2000). CT imaging of trunk muscles in chronic low back pain patients and healthy control subjects. Eur Spine J, 9(4), 266-272.

Dehghan, M., \& Farahbod, F. (2014). The efficacy of thermotherapy and cryotherapy on pain relief in patients with acute low back pain, a clinical trial study. J Clin Diagn Res, 8(9), LC01-04. doi:10.7860/JCDR/2014/7404.4818

Deyo, R. A., Mirza, S. K., \& Martin, B. I. (2006). Back pain prevalence and visit rates: estimates from U.S. national surveys, 2002. Spine (Phila Pa 1976), 31(23), 2724-2727. doi:10.1097/01.brs.0000244618.06877.cd

Friedrich, M., Gittler, G., Halberstadt, Y., Cermak, T., \& Heiller, I. (1998). Combined exercise and motivation program: effect on the compliance and level of disability of patients with chronic low back pain: a randomized controlled trial. Arch Phys Med Rehabil, 79(5), 475487.

Gard, G., \& Larsson, A. (2003). Focus on motivation in the work rehabilitation planning process: a qualitative study from the employer's perspective. J Occup Rehabil, 13(3), 159-167.

Garra, G., Singer, A. J., Leno, R., Taira, B. R., Gupta, N., Mathaikutty, B., \& Thode, H. J. (2010). Heat or cold packs for neck and back strain: a randomized controlled trial of efficacy. Acad Emerg Med, 17(5), 484-489. doi:10.1111/j.1553-2712.2010.00735.x 
Gaskell, S. (2009). Three Navy SEALS freed Capt. Phillips from pirates with simultaneous shots from 100 feet away. NY Daily News.

Gordon, R., \& Bloxham, S. (2016). A Systematic Review of the Effects of Exercise and Physical Activity on Non-Specific Chronic Low Back Pain. Healthcare (Basel), 4(2). doi:10.3390/healthcare4020022

Graham, J. F. (2000). Exercise: Deadlift. Strength and Conditioning Journal, 22(5), 18-20.

Hayden, J. A., van Tulder, M. W., Malmivaara, A. V., \& Koes, B. W. (2005). Meta-analysis: exercise therapy for nonspecific low back pain. Ann Intern Med, 142(9), 765-775.

Homayouni, K., Foruzi, S., \& Kalhori, F. (2016). Effects of kinesiotaping versus non-steroidal anti-inflammatory drugs and physical therapy for treatment of pes anserinus tendinobursitis: A randomized comparative clinical trial. Phys Sportsmed, 44(3), 252-256. doi:10.1080/00913847.2016.1199251

Horn, K. K., Jennings, S., Richardson, G., Vliet, D. V., Hefford, C., \& Abbott, J. H. (2012). The patient-specific functional scale: psychometrics, clinimetrics, and application as a clinical outcome measure. J Orthop Sports Phys Ther, 42(1), 30-42. doi:10.2519/jospt.2012.3727

Hughes, S. L., Seymour, R. B., Campbell, R., Pollak, N., Huber, G., \& Sharma, L. (2004). Impact of the fit and strong intervention on older adults with osteoarthritis. Gerontologist, 44(2), 217-228.

Hughes, S. L., Seymour, R. B., Campbell, R. T., Huber, G., Pollak, N., Sharma, L., \& Desai, P. (2006). Long-term impact of Fit and Strong! on older adults with osteoarthritis. Gerontologist, 46(6), 801-814. 
Jordan, J. L., Holden, M. A., Mason, E. E., \& Foster, N. E. (2010). Interventions to improve adherence to exercise for chronic musculoskeletal pain in adults. Cochrane Database Syst $\operatorname{Rev}(1)$, CD005956. doi:10.1002/14651858.CD005956.pub2

Kase, K., Wallis, J., Kase, T. (2003). Clinical therapeutics applications of the Kinesio Taping method. Tokyo: Ken Ikai Co Ltd.

killustrated.com. ((n.d.)). Deadlift strength standards. Retrieved from http://www.lonkilgore.com/freebies/deadlift_standards_pounds_small.pdf

Knox, J., Orchowski, J., Scher, D. L., Owens, B. D., Burks, R., \& Belmont, P. J. (2011). The incidence of low back pain in active duty United States military service members. Spine (Phila Pa 1976), 36(18), 1492-1500. doi:10.1097/BRS.0b013e3181f40ddd

Li, Y., McClure, P. W., \& Pratt, N. (1996). The effect of hamstring muscle stretching on standing posture and on lumbar and hip motions during forward bending. Phys Ther, 76(8), 836-845; discussion 845-839.

Lim, E. C., \& Tay, M. G. (2015). Kinesio taping in musculoskeletal pain and disability that lasts for more than 4 weeks: is it time to peel off the tape and throw it out with the sweat? A systematic review with meta-analysis focused on pain and also methods of tape application. Br J Sports Med, 49(24), 1558-1566. doi:10.1136/bjsports-2014-094151

Makeoverfitness. ((n.d)). How to conduct the sit and reach test. Retrieved from http://www.makeoverfitness.com/flexibility-test/6212-how-to-conduct-the-sit-and-reachtest

Malanga, G. A., Yan, N., \& Stark, J. (2015). Mechanisms and efficacy of heat and cold therapies for musculoskeletal injury. Postgrad Med, 127(1), 57-65. doi:10.1080/00325481.2015.992719 
Mannion, A. F., Wieser, S., \& Elfering, A. (2013). Association between beliefs and care-seeking behavior for low back pain. Spine (Phila Pa 1976), 38(12), 1016-1025.

Melnyk, B. M., Fineout-Overholt, E. . (2015). Evidence-based practice in nursing \& healthcare a guide to best practice (Third ed.). Philadelphia, PA: Wolters Kluwer Health.

Myrer, J. W., Measom, G., \& Fellingham, G. W. (1998). Temperature changes in the human leg during and after two methods of cryotherapy. Journal of athletic training, 33(1), 25.

Nadler, S. F., Weingand, K., \& Kruse, R. J. (2004). The physiologic basis and clinical applications of cryotherapy and thermotherapy for the pain practitioner. Pain Physician, 7(3), 395-399.

Olive, J. L., Hollis, B., Mattson, E., \& Topp, R. (2010). Vascular conductance is reduced after menthol or cold application. Clin J Sport Med, 20(5), 372-376. doi:10.1227/NEU.0b013e3181e57bca

Petrofsky, J. S., Laymon, M. S., Alshammari, F. S., \& Lee, H. (2016). Use of Low Level of Continuous Heat as an Adjunct to Physical Therapy Improves Knee Pain Recovery and the Compliance for Home Exercise in Patients With Chronic Knee Pain: A Randomized Controlled Trial. J Strength Cond Res, 30(11), 3107-3115.

doi:10.1519/JSC.0000000000001409

Prevention, C. f. D. C. a. (2016a). CDC Releases Guideline for Prescribing Opioids for Chronic Pain [Press release]. Retrieved from https://www.cdc.gov/media/releases/2016/p0315prescribing-opioids-guidelines.html

Prevention, C. f. D. C. a. $(2016,2016)$. Drug overdose deaths in the United States continue to increase in 2015. Understanding the Epidemic. Retrieved from https://www.cdc.gov/drugoverdose/epidemic/index.html 
Prevention, C. f. D. C. a. (2016b). Side Effects. Prescription Opioids. Retrieved from https://www.cdc.gov/drugoverdose/opioids/prescribed.html

Qaseem, A., Wilt, T. J., McLean, R. M., Forciea, M. A., \& Clinical Guidelines Committee of the American College of, P. (2017). Noninvasive Treatments for Acute, Subacute, and Chronic Low Back Pain: A Clinical Practice Guideline From the American College of Physicians. Ann Intern Med. doi:10.7326/M16-2367

Rippetoe, M., Kilgore, L., Pendley, G. (2006). Practical programming for strength training. Wichita Falls, TX: The Aasgaard Company

Strand, S. L., Hjelm, J., Shoepe, T. C., \& Fajardo, M. A. (2014). Norms for an isometric muscle endurance test. J Hum Kinet, 40, 93-102. doi:10.2478/hukin-2014-0011

Stratford, P., Gill, C., Westaway, M., \& Binkley, J. (1995). Assessing disability and change on individual patients: a report of a patient specific measure. Physiotherapy canada, 47(4), 258-263.

Sullivan, M. J., Feuerstein, M., Gatchel, R., Linton, S. J., \& Pransky, G. (2005). Integrating psychosocial and behavioral interventions to achieve optimal rehabilitation outcomes. $J$ Occup Rehabil, 15(4), 475-489. doi:10.1007/s10926-005-8029-9

Sundstrup, E., Jakobsen, M. D., Brandt, M., Jay, K., Colado, J. C., Wang, Y., \& Andersen, L. L. (2014). Acute effect of topical menthol on chronic pain in slaughterhouse workers with carpal tunnel syndrome: triple-blind, randomized placebo-controlled trial. Rehabil Res Pract, 2014, 310913. doi:10.1155/2014/310913

Thomas, D. L. (2004). The U.S. Army: A Business? Return on Investment? Military.com. Retrieved from http://www.military.com/NewContent/0,13190,120304_ArmyBusinessP1,00.html 
Thorlacius, H., Vollmar, B., Westermann, S., Torkvist, L., \& Menger, M. D. (1998). Effects of local cooling on microvascular hemodynamics and leukocyte adhesion in the striated muscle of hamsters. J Trauma, 45(4), 715-719.

Titler, M. G., Kleiber, C., Steelman, V. J., Rakel, B. A., Budreau, G., Everett, L. Q., ... Goode, C. J. (2001). The Iowa Model of Evidence-Based Practice to Promote Quality Care. Crit Care Nurs Clin North Am, 13(4), 497-509.

Topp, R., Ledford, E. R., \& Jacks, D. E. (2013). Topical menthol, ice, peripheral blood flow, and perceived discomfort. J Athl Train, 48(2), 220-225. doi:10.4085/1062-6050-48.1.19

Ullrich, P. F. (2009). Low-Impact Aerobic Exercise. Spine-health.

Ullrich, P. F. (2014). Stretching for Back Pain Relief. Spine-health. Retrieved from http://www.spine-health.com/wellness/exercise/low-impact-aerobic-exercise

Williamson, A., \& Hoggart, B. (2005). Pain: a review of three commonly used pain rating scales. J Clin Nurs, 14(7), 798-804. doi:10.1111/j.1365-2702.2005.01121.x

Wood, R. (2008). Sit and rech test for Navy Physical readiness. Retrieved from http://www.topendsports.com/testing/tests/sit-reach-prt.htm

Wright, C. J., \& Schutte, N. S. (2014). The relationship between greater mindfulness and less subjective experience of chronic pain: Mediating functions of pain management self efficacy and emotional intelligence. Australian Journal of Psychology, 66(3), 181-186.

Zhang, J., Enix, D., Snyder, B., Giggey, K., \& Tepe, R. (2008). Effects of Biofreeze and chiropractic adjustments on acute low back pain: a pilot study. J Chiropr Med, 7(2), 5965. doi:10.1016/j.jcme.2008.02.004 
Zoroya, G. (2011). General's story a warning about use of painkillers. USA Today. Retrieved from http://usatoday30.usatoday.com/news/military/2011-01-271Adruggeneral27_CV_N.htm 
Table 3

Cost/Benefit Summary of EBP Project

\begin{tabular}{|c|c|c|}
\hline Resources & Cost & Rationale \\
\hline $\begin{array}{l}\text { Non-pharmacological pain } \\
\text { management kit (BioFreeze, } \\
\text { TheraPearl, Theraband, } \\
\text { Kinesiology tape, educational } \\
\text { materials) }\end{array}$ & $\$ 0$ & $\begin{array}{l}\text { Required for } 5 \text { non- } \\
\text { pharmacological } \\
\text { interventions. Educational } \\
\text { and written behavioral } \\
\text { materials included in kit. } \\
\text { These materials were } \\
\text { provided through a grant. }\end{array}$ \\
\hline Patient Education & $\$ 0$ & $\begin{array}{l}\text { No Cost: Performed by DNP } \\
\text { Student }\end{array}$ \\
\hline $\begin{array}{l}\text { Recruitment (flyers) } \\
-100 \text { copies }\end{array}$ & $\$ 0$ & $\begin{array}{l}\text { Posted for CLBP recruitment. } \\
\text { Budgeted through grant } \\
\text { funds. }\end{array}$ \\
\hline $\begin{array}{l}\text { Data Collection Forms } \\
-25 \text { copies }\end{array}$ & $\$ 0$ & $\begin{array}{l}\text { Used by DNP student to } \\
\text { collect data at baseline, week } \\
1 \text {, and week } 4 \text {. Budgeted } \\
\text { through grant funds. }\end{array}$ \\
\hline Clinical Site/Evaluation Tools & $\$ 0$ & $\begin{array}{l}\text { No Cost: all evaluation tools, } \\
\text { weights, matts, fitness } \\
\text { equipment provided at } \\
\text { clinical site }\end{array}$ \\
\hline Benefit & Cost & Rationale \\
\hline $\begin{array}{l}\text { Soldier Retention } \\
-11 \text { soldiers } x \$ 35,000 \text { in } \\
\text { training costs }\end{array}$ & $\$ 385,000.00$ & $\begin{array}{l}\text { Average cost to train each } \\
\text { soldier who is expected to be } \\
\text { serving at full capacity. }\end{array}$ \\
\hline $\begin{array}{l}\text { Cost Savings } \\
11 \text { military personnel } \\
\$ 385,000 \text { (training costs - } \\
\text { resource costs) }\end{array}$ & $\$ 385,000.00$ & $\begin{array}{l}\text { Potential savings for } \\
\text { retaining } 25 \text { healthy full } \\
\text { functional active duty } \\
\text { personnel }\end{array}$ \\
\hline
\end{tabular}


Appendix A

\section{Do you suffer from chronic low back pain?}

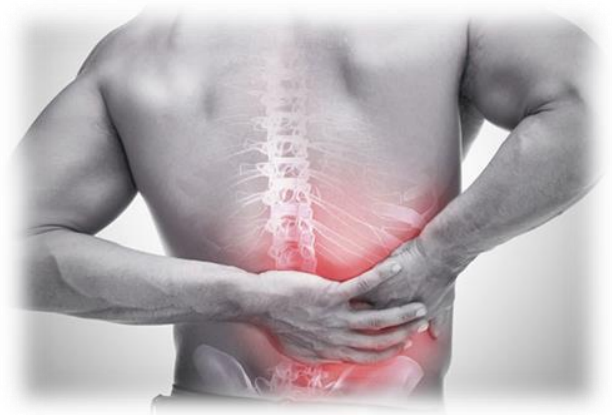

Heidi Sterling, RN, Doctoral Nurse Practitioner student from the University of San Diego is conducting a project titled Chronic Low Back Pain

Management in order to determine if a non-drug pain management kit can help:

- Decrease Low Back Pain

- Promote Greater Functional Ability

- Assist with Desired Level of Unit Participation

If you have low back pain lasting greater than 4 weeks, you qualify for this FREE program

Location - on site assessment at Navy Amphibious Base Coronado

Project:

- No prior medical screening required for inclusion

- Visit the clinical site 3 times for 15 to 45 minutes, over 4 weeks

- Get a FREE non-drug pain management kit including Biofreeze ${ }^{\circledR}$, Kinesiology Tape, thermotherapy, low back exercise, and behavioral interventions

- Complete questionnaires and a physical functioning test along with a simple daily diary

If you are interested in learning more about this project contact Heidi Sterling, RN, DNP Student

(619) 886-5611

pain.relief.toolkit@gmail.com

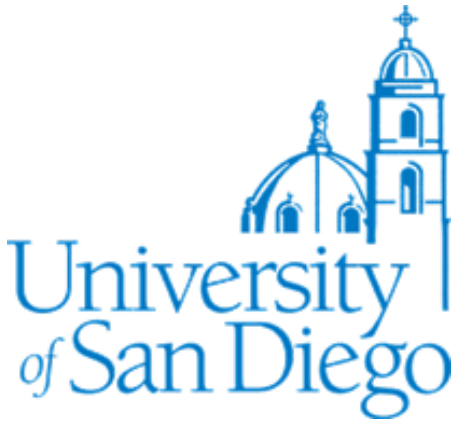




\section{Appendix B}

Interventions:

1. BioFreeze (roll on): Apply to affected area in the morning and as needed throughout the day in response to pain. Apply prior to engaging in training exercises or any other moderate intensity activity up to 4 total times per day.

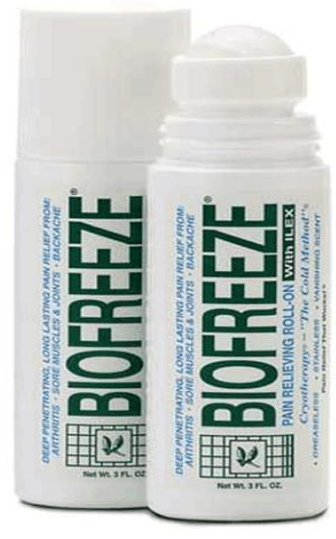

2. Kinesiology Tape: Apply to skin over painful area stretching tape at $25 \%-50 \%$ tension. Reapply every 3 days or as needed when tape fails to adhere $>80 \%$. Tape should remain in place at all times. SEE INSTRUCTIONS

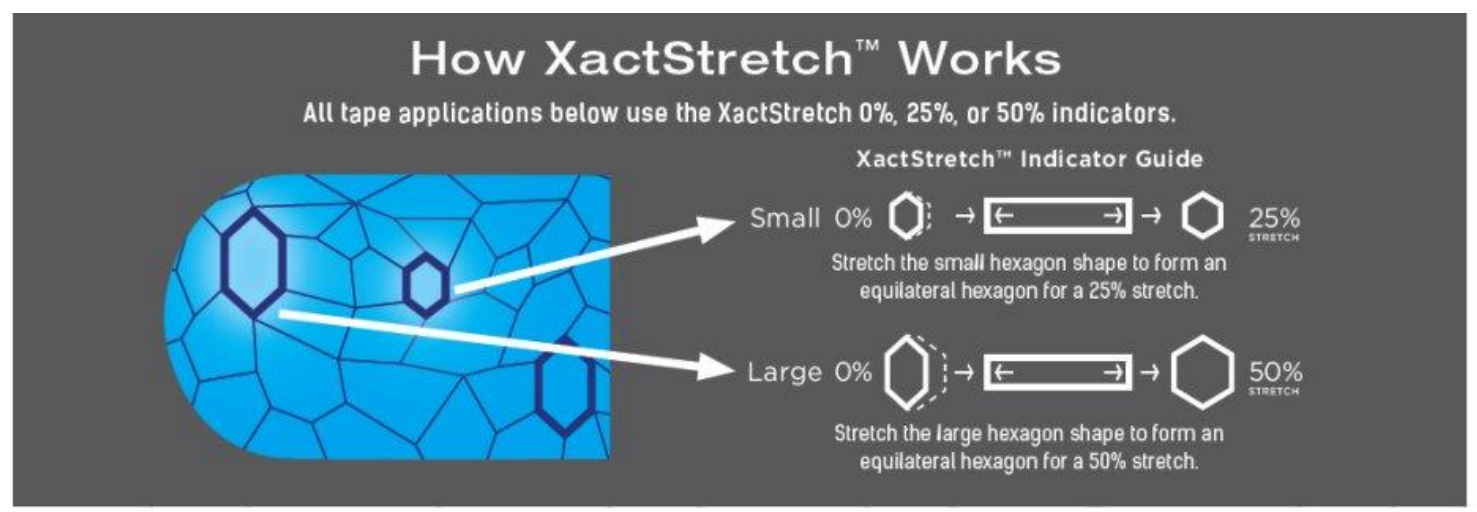

Before Application:

1. Wash area to remove oil, dirt, creams or lotions

2. If possible remove hair from application area

3. Apply at least 60 minutes before exercising, showering, or exposing to water

Standard Tapping Application Guidelines: 
1. Break paper through tape and peel away backing without touching the adhesive.

2. Always apply the last 1-2 inches of tape without any stretch. Do not overstretch the tape.

3. After applying, rub the tape toward each end to further activate the adhesive.

4. Tape removal: remove tape slowly, do not rip tape off skin.

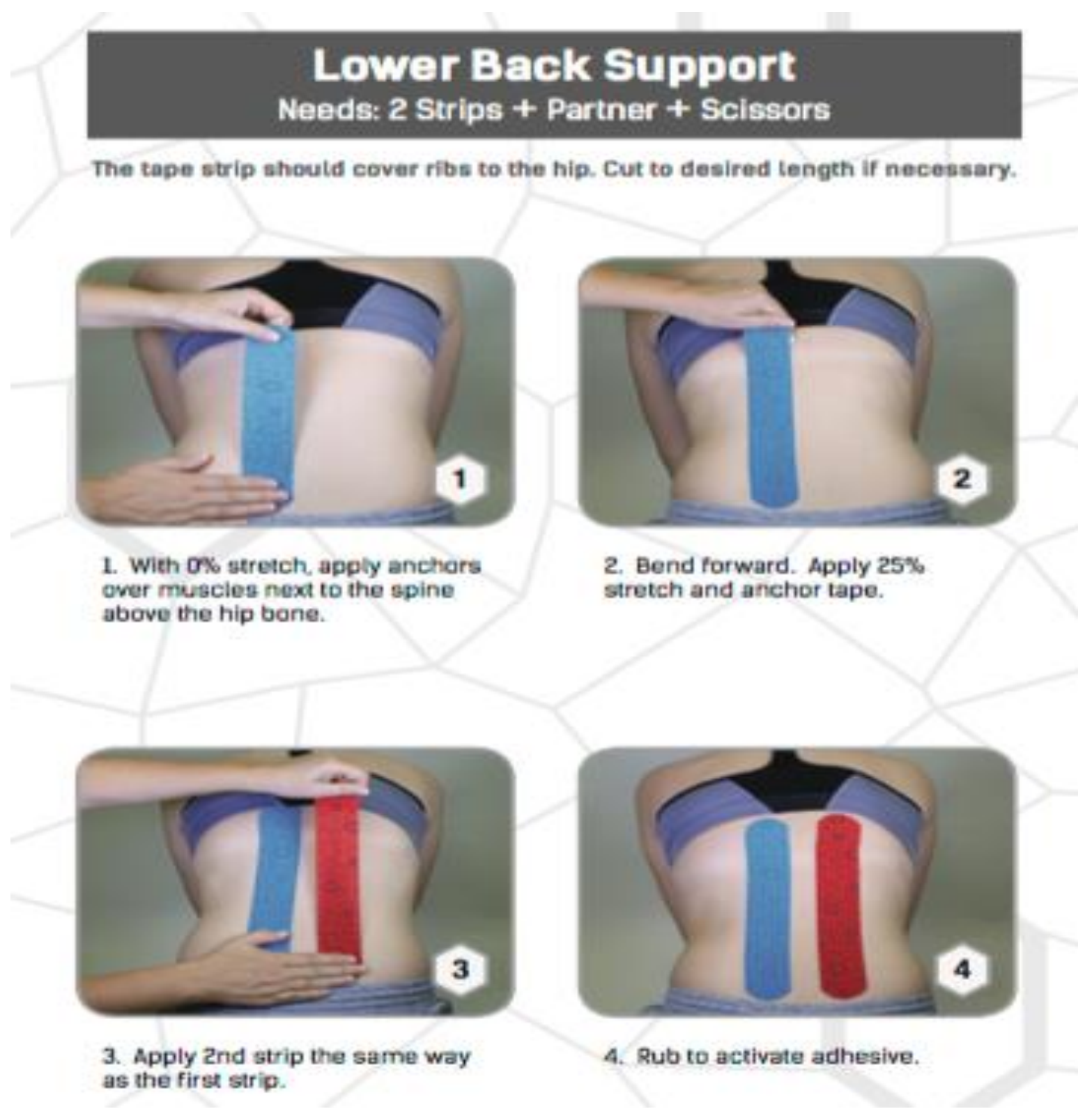

3. Thermal Therapy [Warm or cool TheraPearl, or other ice/heat pack]: For cold TheraPearl freeze for at least 2 hours. Apply following engagement in exercise or any other moderate intensity activity for up to 20 minutes at a time, remove for a minimum of 20 minutes, and reapply as needed. For warm TheraPearl, heat for 65 seconds in a 700 watt microwave, 55 seconds in a 1000 watt microwave, and 45 seconds in a 1250 watt microwave. Test pack 
temperature, heat for an additional 5 seconds as needed. Apply warm TheraPearl prior to physical activity for 20 minutes.

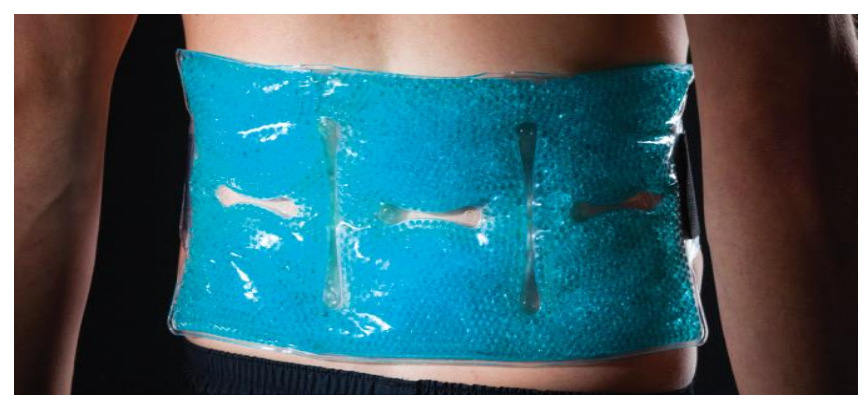

4. Exercise Training: Exercise training includes flexibility and strength training specific exercises for the low back. Flexibility exercise will be performed 3 days per week and strength exercises will be performed on 3 alternate days with a seventh day of rest (Figure 2). Strength exercises will initially be with gravity resistance and progress to resistance using a variety of TheraBands that will be prescribed to the participant.

Flexibility: 3 exercises performed for 3 days per week. There will be 12 total days of flexibility exercise during the 4 weeks. Hold each position for 15-30 seconds and repeat each exercise 3 times in one session.

a) Sit and Reach Hamstring Stretch

i. Sit on the floor with your right leg extended in front of you and your toes pointing to the ceiling. Your left leg should be bent and relaxed on the floor with the sole of the left foot facing the right thigh. Lean forward at your waist to bring your upper body down toward your right leg. Keep your back straight as you come down and bring your chest down to the leg. Come down until you feel a light stretch in the back of your right leg. Switch legs and perform same stretch on the opposite leg.

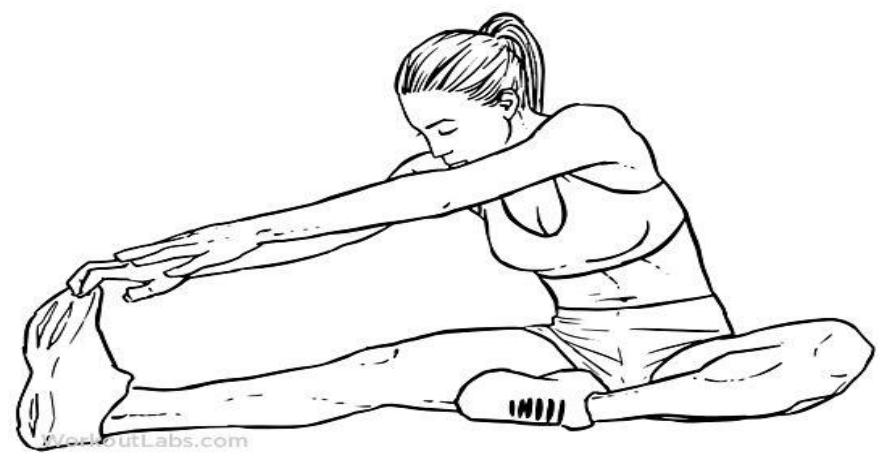

b) Cat and Camel Back Stretch

i. Get down on your hands and knees. Let your stomach sag, allowing your back to curve downward. Hold this position for 5 seconds. Then arch your back and hold for 5 seconds. 

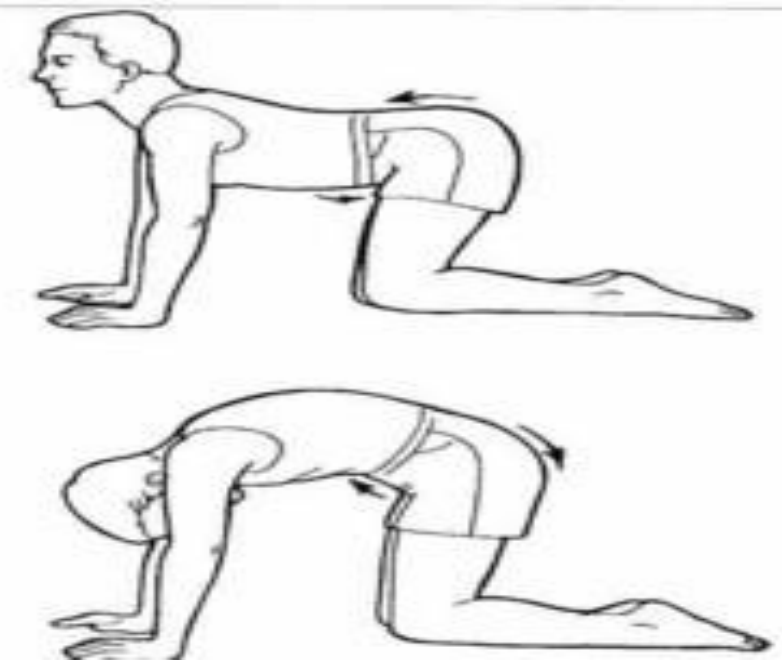

c) Piriformis Stretch

i. Lying on your back with both knees bent, rest the ankle of one leg over the opposite knee. Grasp the thigh of the bottom leg and pull that knee toward your chest. You will feel a stretch along the buttocks and possibly along the outside of your hip on the top leg. Switch legs and perform same stretch on opposite side.

Piriformis Stretch:

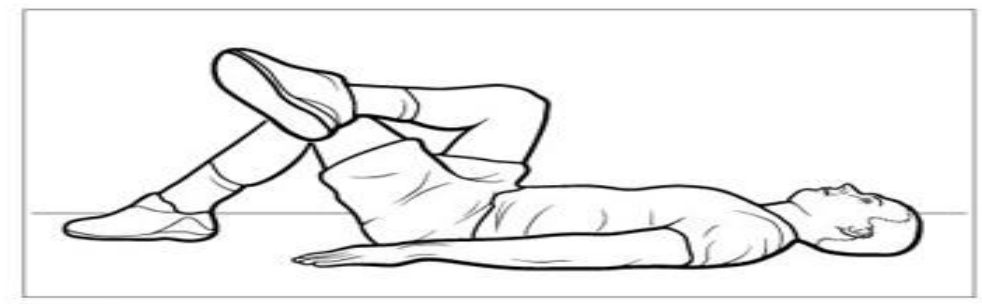

Fig. 1

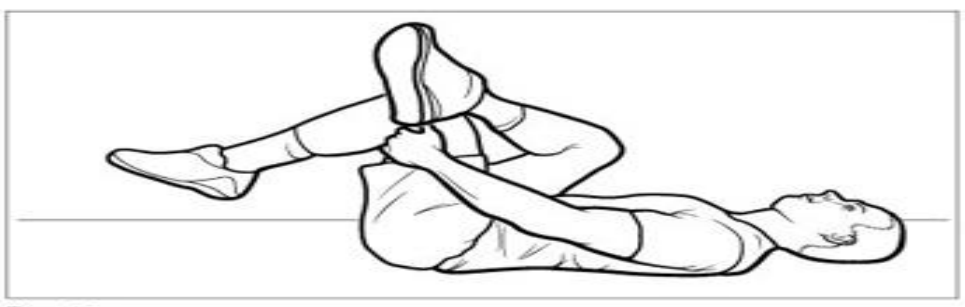

Fig. 2

Strength: 4 exercises performed 3 days per week. There will be a total of 12 days of strengthening exercise during the 4 weeks performed with Theraband CLX. Theraband CLX is a form of Theraband that provides unique grip loops at the end of each band allowing for more versatility and better grip. Exercises are initially demonstrated against gravity and then progress starting with the green Theraband CLX (Figure 1). The number of sets and repetitions that 
correlate with each day and color of Theraband are explained in Figure 2. You might find that you need a different color for the various exercises. If you can easily complete more than 8 repetitions with that color, then you can move to the next higher level of resistance until you find a color in which you can complete 8 repetitions with minimal discomfort. Maintain that level (color) until you find that you can move above the prescribed number of repetitions for that week.

- The correct level of resistance is defined as being able to perform the prescribed number of sets and repetitions with full range of motion and in proper body alignment.

- A level of resistance that is too difficult is defined as not being able to perform the prescribed number of sets and repetitions with full range of motion and in proper body alignment or without stopping.

- A level of resistance that is too easy is defined as being able to perform more the prescribed number of sets and repetitions with full range of motion and in proper body alignment.

Figure 1.

\begin{tabular}{|l|l|c|}
\hline Color of Theraband & Level of Resistance \\
\hline Green & Heavy & \multirow{2}{*}{ Lightest } \\
\hline Blue & Extra Heavy & \\
\hline Black & Special Heavy & \\
\hline Silver & Super Heavy & \multirow{2}{*}{ Heaviest } \\
\hline Gold & Maximum & \\
\hline
\end{tabular}

a) Loop Bridge and Hip Abduction in Supine/Pelvic Tilt

i. Loop a medium band around pelvis with feet shoulder width apart. Holding a grip loop in each hand lift rear off mat while pushing knees outward toward band. Hold and slowly return. 

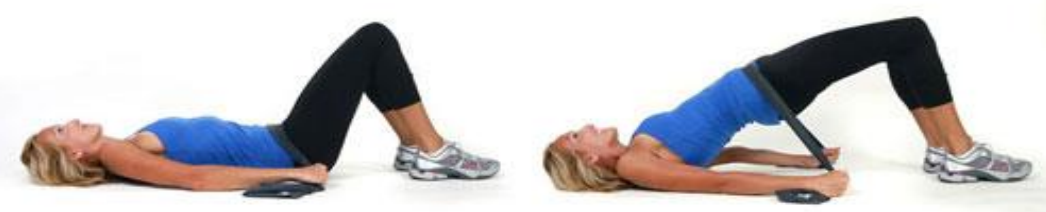

b) Lumbar extension in long sitting

i. Sit on floor with knees straight and center of band around the feet. Grasp each grip loop at the ends of the Theraband at chest level. Keeping your back straight and upright, lean backward away from your feet. Don't arch your back. Hold and slowly return.

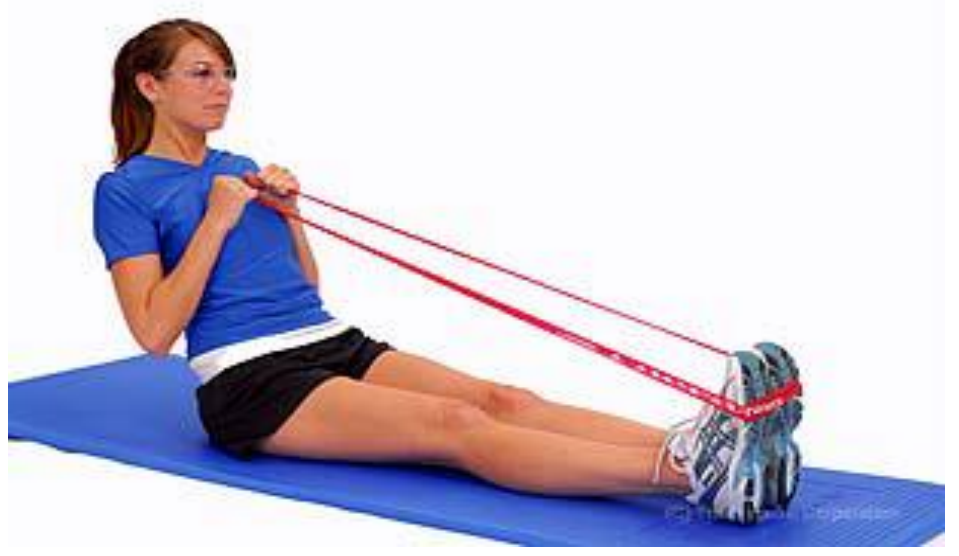

c) Leg Extension in Quadruped

i. Begin in quadruped position on elbows and knees. With middle of the Theraband around your foot, stabilize the ends by holding the grip loops with your hands on the floor. Extend leg backward, keeping your back straight. Hold and slowly return 


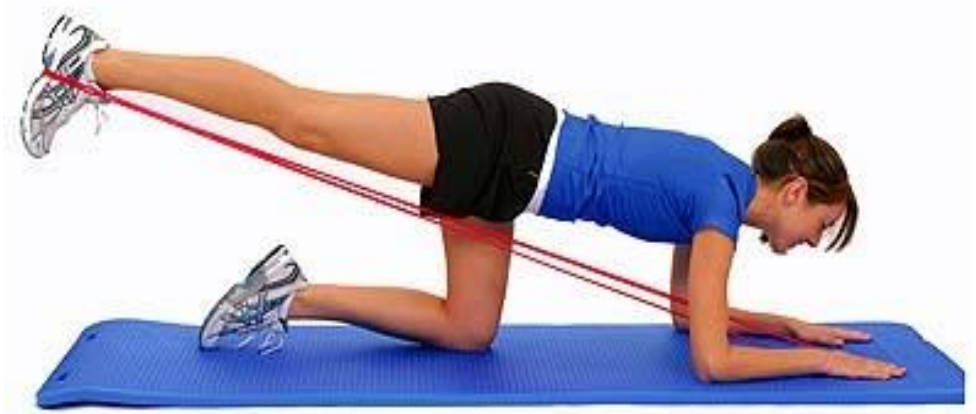

d) Standing Lateral Arm Raise

i. Place one foot on the center of the Theraband, with a closed handgrip and thumbs pointed upward begin raising arms to shoulder level, maintain a 30-degree angle in front of your body. Be sure not to shrug your shoulder and keep a straight back. Hold briefly and return to starting position.

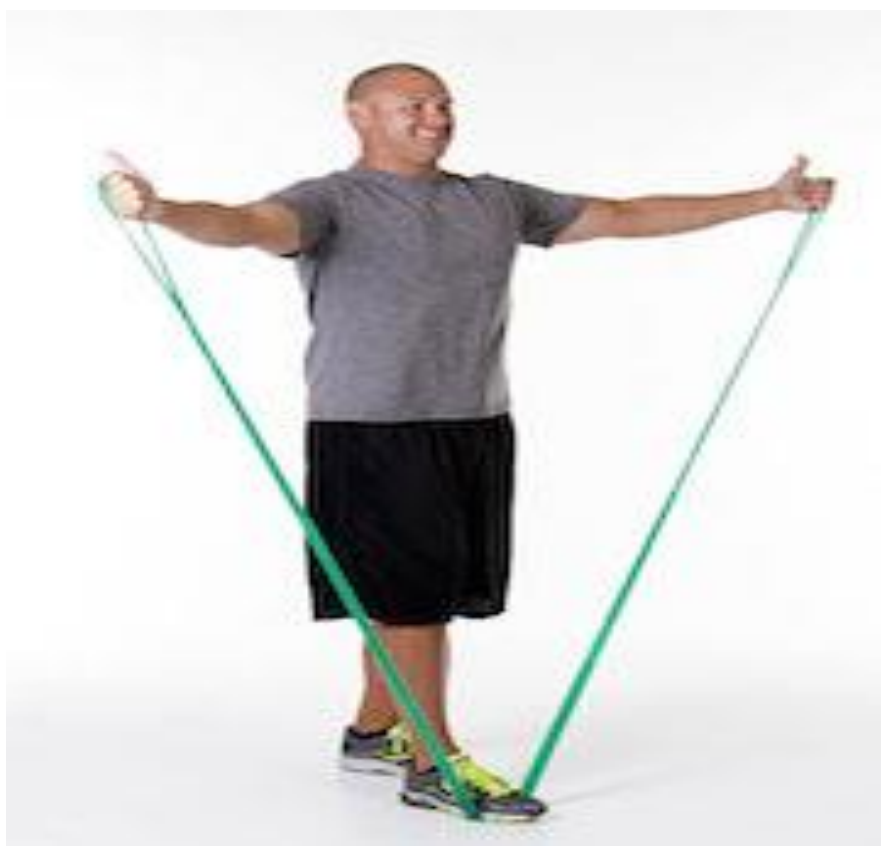

5. Behavioral Component: Behavioral components include setting goals, working with a buddy, and keeping a graph of their progress. It is not required that all three of these are performed, however we recommend trying all three techniques and then selecting the one(s) that work for you.

a) Set realistic goals and milestones to progressing toward those goals 
- Realistic goals are ones you can measure and achieve within a reasonable amount of time

- Share your goals with others, post them on the refrigerator

- Celebrate achievement of weekly goals

- Anticipate and plan for setbacks - set a schedule and a "back up" schedule

b) Working with a buddy (spouse, friend, child)

- Builds commitment to continuing with your pain management program

- Identify a buddy who will help you maintain and monitor your pain management program includes setting goals and keeping track of your progress

c) Keep a graph of your progress.

- Graphing or keeping a record of your progress will allow you to "see" your progress with your pain management program

- Share this graph with your pain management buddy

Figure 2. Recommended Intervention Schedule. Behavioral, Kinesiology Tape, Biofreeze®, and thermotherapy should be used daily in addition to flexibility, strength, and rest days. 


\begin{tabular}{|c|c|c|c|}
\hline Day & Exercise & Sets x Reps & Resistance \\
\hline 1 & Strength & $3 \times 8$ & Gravity (no band) \\
\hline 2 & Flexibility & & \\
\hline 3 & Strength & $3 \times 8$ & Green Band \\
\hline 4 & Flexibility & & \\
\hline 5 & Strength & $3 \times 10$ & Green Band \\
\hline 6 & Flexibility & & \\
\hline 7 & Rest Day & & \\
\hline 8 & Strength & $3 \times 12$ & Green Band \\
\hline 9 & Flexibility & & \\
\hline 10 & Strength & $3 \times 8$ & Blue Band \\
\hline 11 & Flexibility & & \\
\hline 12 & Strength & $3 \times 10$ & Blue Band \\
\hline 13 & Flexibility & & \\
\hline 14 & Rest Day & & \\
\hline 15 & Strength & $3 \times 12$ & Blue Band \\
\hline 16 & Flexibility & & \\
\hline 17 & Strength & $3 \times 8$ & Black Band (if tolerated) \\
\hline 18 & Flexibility & & \\
\hline 19 & Strength & $3 \times 10$ & Black Band \\
\hline 20 & Flexibility & & \\
\hline 21 & Rest Day & & \\
\hline 22 & Strength & $3 \times 12$ & Black Band \\
\hline 23 & Flexibility & & \\
\hline
\end{tabular}




\begin{tabular}{|c|c|c|l|}
\hline 24 & Strength & $3 \times 8$ & Silver Band (if tolerated) \\
\hline 25 & Flexibility & & \\
\hline 26 & Strength & $3 \times 10$ & Silver Band \\
\hline 27 & Flexibility & & \\
\hline 28 & Rest Day & & \\
\hline
\end{tabular}




\section{Appendix C: Demographic Questionnaire}

Participant Name

Date

Phone number 1 Phone number 2

Surgery Type Date of Surgery

1. Gender (circle ): Male Female

2. Age

3. What is your occupation?

For how many years?

4. Do you regularly engage in exercise at least once per week?

No Yes Type/amount/frequency

5. How long have you experienced pain in [location]?

6. Since your Surgery what is the average amount of prescription pain medication you have consumed per day?

Drug Name Number of Pills

7. Indicate on the line below with an " $\mathrm{X}$ " what you believe is an acceptable level of pain that would allow you to carry on your desired activities of daily living

1

.10

Very Minor

Worst Possible 
8. Do you have any previously diagnosed health problems:

\begin{tabular}{|l|l|l|}
\hline $\begin{array}{l}\text { Condition Diagnosed by a } \\
\text { Physician }\end{array}$ & $\begin{array}{l}\text { How long } \\
\text { have you } \\
\text { had this } \\
\text { condition? }\end{array}$ & On the average day how do you treat this condition? \\
\hline & & $\begin{array}{l}\text { Medications: } \\
\text { OTC: } \\
\text { Other Therapies: }\end{array}$ \\
\hline & $\begin{array}{l}\text { Medications: } \\
\text { OTC } \\
\text { Other Therapies: }\end{array}$ \\
\hline & $\begin{array}{l}\text { Medications: } \\
\text { OTC } \\
\text { Other Therapies: }\end{array}$ \\
\hline & $\begin{array}{l}\text { Medications: } \\
\text { OTC } \\
\text { Other Therapies: }\end{array}$ \\
\hline
\end{tabular}


9. Do you regularly take any other medications that you haven't listed above?

\begin{tabular}{|l|l|l|}
\hline Medication & Dose/frequency & $\begin{array}{c}\text { Why do you take this } \\
\text { medication? }\end{array}$ \\
\hline & & \\
\hline & & \\
\hline & & \\
\hline & & \\
\hline & & \\
\hline
\end{tabular}




\section{Appendix D}

The Patient-Specific Functional Scale

Participant Name

This useful questionnaire can be used to quantify activity limitation and measure functional outcome for patients with any chronic health condition.

Clinician to read and fill in below: Complete at the end of the history and prior to physical examination.

Initial Assessment:

I am going to ask you to identify at least three important activities that you are unable to do or are having difficulty with as a result of your [__Painful condition___]. Today, are there any activities that you are unable to do or having difficulty with because of your [__Painful condition___]? (Clinician: show scale to patient and have the patient rate each activity. Previous scores should not be disclosed to the patient).

Follow-up Assessments:

When I assessed you on (state previous assessment date), you told me that you had difficulty with (read all activities from list at a time). Today, do you still have difficulty with: (read and have patient score each item in the list)?

\section{Patient-specific activity scoring scheme (Point to one number):}

$\begin{array}{lllllllllll}0 & 1 & 2 & 3 & 4 & 5 & 6 & 7 & 8 & 9 & 10\end{array}$

Unable to

Able to perform

Perform

activity at the same

Activity

level as before

Injury or problem

(Date and Score)

\begin{tabular}{|l|l|l|l|l|}
\hline \multicolumn{1}{|c|}{ Activity } & Baseline score & 1-Week & 4-Weeks & comments \\
\hline 1. & & & & \\
\hline 2. & & & & \\
\hline 3. & & & & \\
\hline 5. & & & & \\
\hline $\begin{array}{l}\text { Total [sum of activities scores /\# of } \\
\text { activities] }\end{array}$ & & & & \\
\hline
\end{tabular}

Total score $=$ sum of the activity scores $/$ number of activities

Minimum detectable change $(90 \% \mathrm{CI})$ for average score $=2$ points

Minimum detectable change $(90 \% \mathrm{CI})$ for single activity score $=3$ points 


\section{Appendix E: Strength and Flexibility Testing}

Sit and Reach Flexibility Test

\begin{tabular}{|l|l|l|l|}
\hline Test Day & Baseline & Week 1 & Week 4 \\
\hline Distance Reached (cm) & & & \\
\hline Pain Level (1-10) & & & \\
\hline
\end{tabular}

\section{Plank}

\begin{tabular}{|l|l|l|l|}
\hline Test Day & Baseline & Week 1 & Week 4 \\
\hline Time Held (seconds) & & & \\
\hline Pain Level (1-10) & & & \\
\hline
\end{tabular}

\section{Deadlift: according to Deadlift Strength Standards}

Initial "untrained" weight to be lifted according to age and individual weight:

\begin{tabular}{|l|l|l|l|}
\hline Test Day & Baseline & Week 1 & Week 4 \\
\hline Weight (lbs) & & & \\
\hline Pain Level (1-10) & & & \\
\hline
\end{tabular}




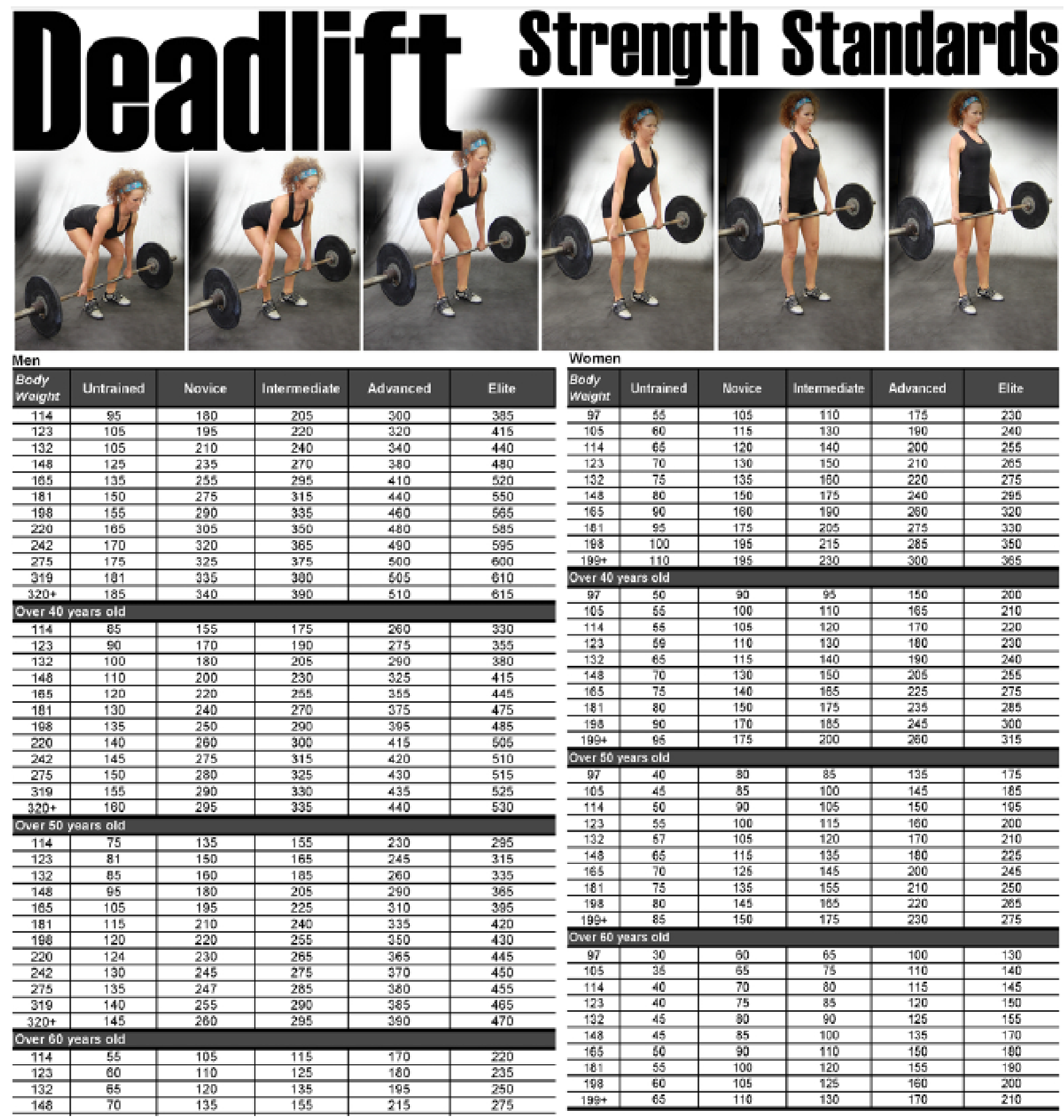


Appendix F: Daily Pain and Treatment Diary

Name

Week: ONE TWO THREE FOUR

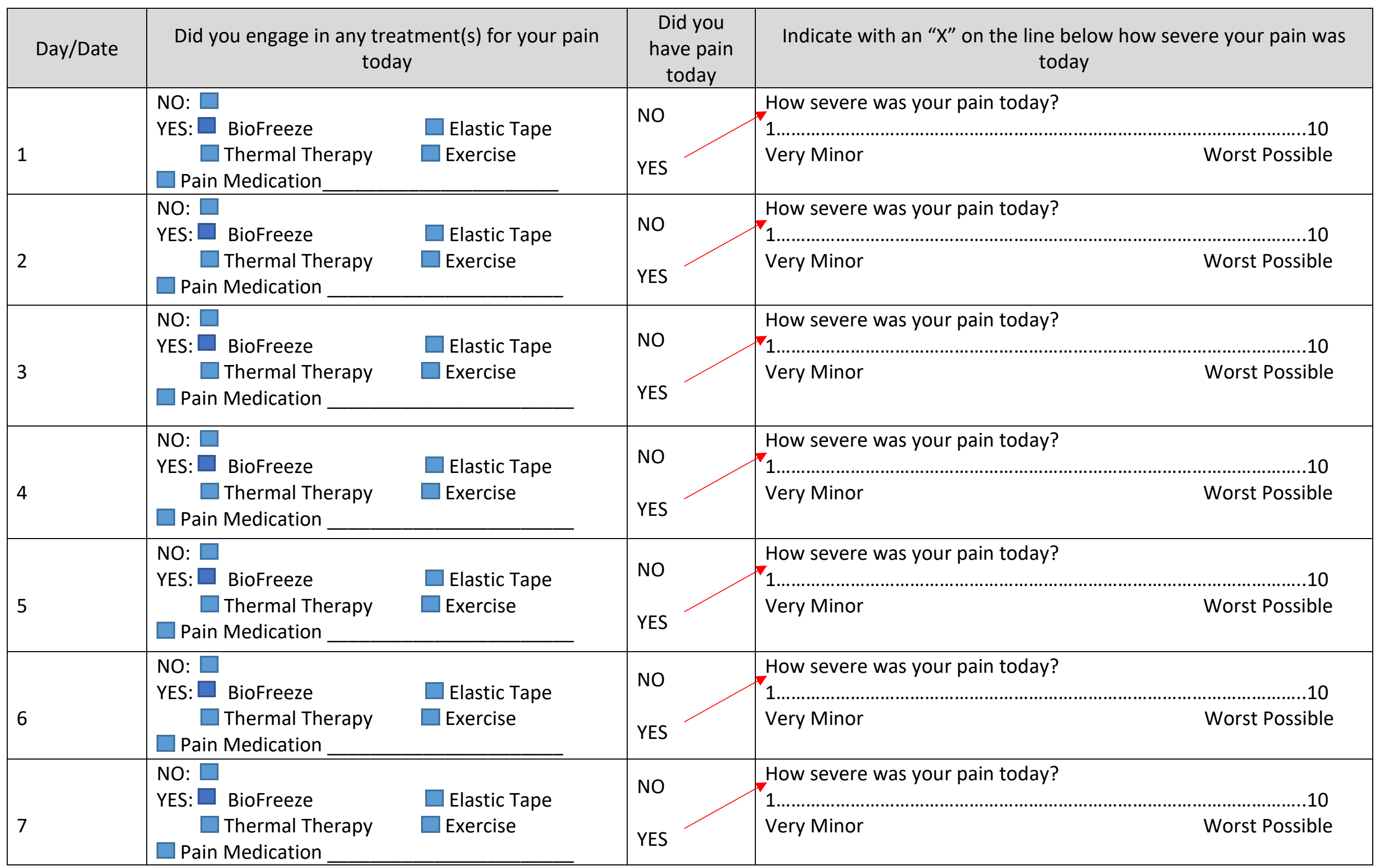




\section{Appendix G: Exit Interview: Subject reports benefits and limitations of the multimodal non-pharmacological Pain Relief Kit.}

1. Which components of the Pain Relief Kit did you find useful in managing your pain and why?

2. Were you able to utilize any of the behavioral components including; setting goals, buddy system, or creating a chart?

3. Which components of the Pain Relief Kit did you NOT find useful in managing your pain and why?

4. What are some other recommendations you have for improving the contents of this Pain Relief Kit?

Resistance Training:

BioFreeze (roll on):

Kinesotape:

Thermal Therapy:

Behavioral Components:

- Set realistic goals and milestones to progressing toward those goals

- Working with a buddy (spouse, friend, child)

- Keep a graph of your progress. 